\title{
METODOLOGÍA ESTABLECIDA POR CRISTO PARA EL CUMPLIMIENTO DE LA MISIÓN
}

\author{
Samuel Naval Dávila \\ Docente DE LA FACULTAD DE TEOLOGIA - UPEU
}

\section{Introducción}

En estos días hablar de métodos para cumplir la misión trasciende las esferas del adventismo e involucra a todo el mundo cristiano. Cada confesión religiosa, desde sus presuposiciones epistemológicas y su teología de la misión, ha bombardeado el mercado cristiano con metodologías de misión hechas en base a las experiencias de sus más sobresalientes representantes. ${ }^{1}$ Muchos métodos cuentan con base bíblica, tienen buenas estrategias, sin embargo, dejan de lado la metodología del dueño de la misión. ${ }^{2}$ El presente estudio tiene como objetivo dar a conocer los métodos usados por Jesucristo para el establecimiento de la misión. Para ello, se estudiará la primera parte del segundo discurso pedagógico registrado en Mateo 10:1-15.

\section{Estudio del contexto}

Los especialistas han estructurado el evangelio de Mateo entre discursos y narrativas. ${ }^{3}$ Los discursos vienen a ser los sermones de Cristo

${ }^{1}$ Cualquier metodología de misión que no está en primer lugar centrado en la teología es mera antropología. Daniel Julio Rode, Teología de la misión (Libertador San Martín, E. Ríos, Facultad de Teología: Universidad Adventista del Plata, 2010), 19.

${ }^{2}$ Toda la Biblia, Antiguo y Nuevo Testamento, es un libro misionero; la revelación del propósito y acción de Dios en misión en la historia humana. Arthur F. Glasser, Charles E. Van Engen, Dean S. Gilliland y Shawn B. Redford, Anouncing the Kingdom: The story of God's Mission in the Bible (Gran Rapids, MI: Baker, 2007), 17.

${ }^{3}$ Donald H. Hagner, "Structure", Matthew 1-13, en Word Biblical Commentary, ed. David A. Hubbard, Glenn W. Barker (Dallas, TX: Word Books Publisher, 1993), 33a:1; Leander E Keck, ed., The New Interpreter's Bible (Nashville, TN: Abingdon Press, 1995), 8:110-3. 
y las narrativas son los relatos, parábolas y descripciones del ministerio de Jesús. ${ }^{4}$ Los discursos se inician con la frase, "cuando terminó Jesús de hablar estas palabras", la cual, con leves modificaciones se repite en cada uno de los cinco principales discursos $(7: 28 ; 11: 1 ; 13: 53 ; 19: 1 ; 26: 1){ }^{5}$

El capítulo 10 es el segundo y gran discurso de Jesús que se encuentra en Mateo. ${ }^{6}$ Es conocido como el sermón de la misión y está precedido por tres párrafos de transición ${ }^{7}$ que sirven como introducción para el desarrollo del sermón.

Para George Knight, prominente teólogo adventista, el discurso está estructurado en tres secciones: la primera sección está dirigida especialmente a los discípulos (10:5-25), la segunda anima a los oyentes a no temer en las adversidades (10:26-31) y la tercera trata de la persecución a manos de las autoridades, amigos y familiares $(10: 32-42){ }^{8}$

Sobre la construcción de las divisiones propuestas en el capítulo de la misión, se construirá el estudio que brindará alcances sobre los pasos usados por Cristo. A continuación se estudiará cada uno de ellos.

\section{Tuvo compasión por las multitudes}

En Mateo 9:35-38, hay una transición previa a la presentación del sermón de la misión. En estos textos se usa la palabra "compasión", que en griego es "esplagjvisthe" que significa "sufrir juntos", "tratar con emociones..." con "simpatía". Es una emoción humana que se manifiesta a partir 2001), 32

${ }^{4}$ Ulrich Luz, Mateo 1-7: el evangelio según san Mateo (Salamanca: Ediciones Sígueme,

${ }^{5}$ David J. Bosch, Misión en transformación-cambios de paradigma en la teología de la misión (Gran Rapids, MI: Libros Desafío, 1991), 86; Leander E Keck, ed. The New Interpreter's Bible, 8:110-3.

${ }^{6}$ George R. Knight, Mattew-The Abundant Life Bible Amplifier (Oshawa: Pacific Press Publishing Association, 1994), 122.

${ }^{7}$ Ibid.

${ }^{8}$ Ibid, 122-5. 
del sufrimiento de otro ser. ${ }^{9}$ Más intensa que la empatía, la compasión describe el entendimiento del estado emocional de otro, y es con frecuencia combinada con un deseo de aliviar o reducir su sufrimiento.

Esta compasión es la misma que había en la deidad por la humanidad. ${ }^{10}$ Es la del Padre que envía en misión a su Hijo (Jn 3:16); Jesús mismo que se describe como el que vino a buscar y a salvar lo que se había perdido (Lc 19:10) y al mismo Espíritu Santo ayudando a las personas para el cumplimiento de la misión. ${ }^{11}$

Jesús tuvo compasión de la gente porque los vio como ovejas sin pastor (9:36). ${ }^{12}$ En el tiempo de Jesús, los encargados de la grey no eran más que asalariados (Jn 10:12,13) y cuando vino el Buen Pastor, encontró que sus ovejas estaban abatidas y dispersas. ${ }^{13}$ Esta enseñanza no se había perdido en Mateo y probablemente tampoco en su audiencia; de hecho Cristo, como el divino pastor, es un tema que aparece a lo largo del libro $(2: 6 ; 25: 31-46)$. El gran Pastor de Israel había venido en la persona de Jesús de Nazaret para pastorear a su rebaño; y a la vez, vino para enviar a sus discípulos para que extiendan su obra y sus enseñanzas. Al respecto, Elena de White declara:

Debemos sentir odio hacia el pecado, y compasión y amor hacia el pecador. Por todas partes, en derredor nuestro, hay almas que van hacia una ruina tan desesperada y terrible como la que sobrecogió a Sodoma. Cada día termina el tiempo de gracia para algunos. Cada hora, algunos pasan más allá del alcance de la misericordia. ¿Y dónde están las voces de amonestación y súplica que induzcan a los pecadores a huir de esta pavorosa condenación? ¿Donde están las manos febrero, 2010).

9"Sufrir”, Wikipedia, http://es.wikipedia.org/wiki/Compasi\%C3\%B3n (consultado: 14 de

${ }^{10}$ Bosch, 477.

${ }^{11}$ Silvano Fausti, Una comunidad lee el evangelio de Mateo (Bogotá: San Pablo, 2007), 198.

${ }^{12}$ Elena de White, El deseado de todas las gentes (Buenos Aires: Asociación Casa Editora Sudamericana, 1990), 124.

${ }^{13}$ Francis Nichol, ed., Comentario bíblico adventista (Buenos Aires: Asociación Casa Editora Sudamericana, 1992), 5:361. 
extendidas para sacar a los pecadores de la muerte? ¿Dónde están los que con humildad y perseverante fe ruegan a Dios por ellos? ${ }^{14}$

Es la compasión por las personas la que hizo buscar obreros para la mies $(9: 37,38)$. Ésta debe ser la motivación que debe sentir todo aquel que participa de la misión de Dios. ${ }^{15}$

El ejemplo de Cristo, al vincularse con los intereses de la humanidad, tiene que ser seguido por todos los que predican su Palabra y por todos los que han recibido el evangelio de su gracia. ${ }^{16}$

\section{Extendió un llamamiento (v. 1a)}

La palabra griega para "llamamiento" es "proskalesámenos" que se traduce como "los llamé", "los invité". Aparece 22 veces en los Evangelios y Hechos; sólo en Mateo aparece seis veces, (15:10, 32; $18: 2,32$ y 20:25) y se usa para llamar a la multitud, a sus discípulos y también a niños. Las veces que Jesucristo aparece llamando a la multitud o a sus discípulos es para transmitirles su preocupación, alguna una enseñanza o para encomendarles la misión. ${ }^{17}$

El llamado tiene una relación directa con la misión, por lo tanto, no puede haber misión sin llamamiento. La frase de Jesús así lo explica: "la mies es mucha, mas los obreros pocos" (9:37). La referencia muestra la necesidad de obreros para trabajar en la viña del Señor al lado del dueño de la mies. ${ }^{18}$ Después de haber mostrado la necesidad de obreros, entonces el evangelista los presenta: ellos son los "doce discípulos". ${ }^{19}$

${ }^{14}$ White, Patriarcas y profetas, 133.

${ }^{15} \mathrm{Nichol}$, Comentario bíblico adventista, 5:361.

${ }^{16}$ White, El deseado de todas las gentes, 126.

${ }^{17}$ Johannes B. Bauer Diccionario de teología bíblica (Barcelona: Herder, 1988), 478.

${ }^{18}$ Rogers Greenway, Vayan y hagan discípulos (Gran Rapids, MI: Libros Desafío, 2002), 13.

${ }^{19}$ George R. Knight, Mateo: colección vida abundante la Biblia amplificada (Buenos Aires: Asociación Casa Editora Sudamericana, 1997), 122. 
El Señor escogió a doce y hizo colaboradores de la misión. Barclay considera que los que fueron llamados no eran personas extraordinarias, porque se ha dicho que Jesús no busca seres humanos extraordinarios sino personas corrientes que puedan convertir las cosas ordinarias en extraordinarias. ${ }^{20}$

Hoy más que nunca resuena en la mente de los que han sido llamados a participar de la misión de Dios. Los campos están blancos para la cosecha, pero faltan obreros. ${ }^{21}$ Más obreros deben responder al llamado de Dios, diciendo: "heme aquí, Señor".

\section{Les dio autoridad (v. 1b)}

Dios califica a todo colaborador suyo equipándolo para hacer frente a la misión. Los discípulos recibieron "autoridad" y "potestad" (10:1). Toda autoridad legítima es derivada de Jesucristo, pues a él le ha sido dada toda potestad en el cielo y en la tierra, y él delega algo de ese honor y de esa potestad en sus ministros. ${ }^{22}$ Esto incluye autoridad sobre todo espíritu inmundo, es decir, para que puedan resistir a Satanás, y en el nombre de Cristo puedan echar fuera a los demonios de la vida de las personas. ${ }^{23}$ Asimismo, recibieron autoridad para "curar toda enfermedad y toda dolencia". Esta declaración está dada siguiendo el mismo pensamiento anterior, que como la autoridad viene de Cristo, él la comparte con los suyos, por tanto, los llamados tendrán poder sobre las enfermedades y las dolencias. ${ }^{24}$

El ministro, como copartícipe de la misión de Dios en todas las circunstancias de su vida, debe actuar sujeto a la autoridad otorgada por el cielo y a la organización que le ha conferido el privilegio de ser su mensajero.

${ }^{20}$ Willian Barclay, Mateo (Barcelona: Clie, 2004), 1:404.

${ }^{21}$ Rogers Greenway, 13.

${ }^{22}$ Henry, Mateo, comentario exegético devocional a toda la Biblia, trad. Francisco la Cueva (Barcelona: CLIE, 1983), 172.

${ }^{23}$ Greenway, 21.

${ }^{24}$ Henry, 175. 


\section{Los instruyó}

Jesús, antes de enviar a los discípulos a cumplir la misión, les dio instrucciones. La primera fue: "por camino de gentiles no vayáis, y en ciudad de samaritanos no entréis". ¿Por qué Jesús hizo esta restricción, cuando él había sido favorablemente acogido en Samaria? Al respecto, Mattew Henry comenta:

Este dicho es opuesto a la actitud de Jesús, debido a que en los evangelios vemos a Jesús hablando con gracia e intimidad con una mujer samaritana y revelándose a ella (Jn 4:4-42), lo vemos contando una de sus historias inmortales acerca del buen samaritano (Lc 10:30-37), le vemos sanando a la hija de una mujer sirofenicia (Mt 15:28). ¿Entonces por qué los prohibió? La respuesta es que los judíos ocupaban un lugar muy especial en el esquema divino; en la justicia divina ellos deberían recibir la primera invitación del evangelio. Otra razón es que los doce no estaban equipados para predicar a los gentiles, no tenían el trasfondo, ni el conocimiento ni la técnica y una tercera razón es que Jesús, como buen estratega, sabía que debía comenzar el evangelio primero por Judea, luego Samaria y los confines de la tierra (Hch 1:8). ${ }^{25}$

La segunda instrucción es: "id más bien a las ovejas perdidas de la casa de Israel" (Mt 10:6). Las palabras "oveja perdida" sugiere la gran preocupación de Jesús por el pueblo de Israel. Él miraba con inmensa compasión y lo quería redimir sacándolo de la senda del pecado. Como el gran Pastor su primer trabajo era atraerlos con cuerdas de amor a todas las ovejas sinceras de la casa de Israel, porque sabía que el tiempo se cumplía y pronto dejarían de ser el pueblo escogido de Dios. ${ }^{26}$

La tercera instrucción es con relación al mensaje: "el reino de los cielos se ha acercado" (Mt 10:7). Éste era el mismo con que Juan el

\footnotetext{
${ }^{25}$ Henry, 177.

${ }^{26}$ Rode, Teología de la misión, 71.
} 
Bautista y el mismo Jesús habían iniciado su ministerio público (Mt 3:2 y 4:17), el cual consistía en sanar enfermos, limpiar leprosos, resucitar muertos, echar fuera demonios y dar de gracia lo que de gracia han recibido $(10: 7-8) .^{27}$

En relación a la tercera instrucción, Jesús les dice: "no os proveáis de oro, ni de plata, ni de cobre para llevar en vuestros cintos; asimismo de alforja para el camino, ni de dos túnicas, ni de sandalias, ni de bordón; porque el obrero es digno de su sostén" (Mt 10:9,10). Con esta declaración, Cristo hace énfasis en la confianza que se debe tener en él. Ya habían sido instruidos a no afanarse por la vida (Mt 6:25 ss), es decir los siervos de Cristo tendrán pan suficiente para proveerse a sí mismos y para compartir con otros. ${ }^{28} \mathrm{Si}$ uno es "hombre de Dios", no debe dar la impresión de ser hombre de negocios e ir buscando ganancias materiales.

En la cuarta instrucción les dice que el obrero es digno de su sustento. Si el discípulo no debe proveer nada para el camino en el cumplimiento de la misión, entonces esta declaración indica que el pueblo de Dios no debe nunca faltar a su deber de dar alimento al mensajero. La expresión "trofe" no quiere decir salario sino sustento, porque para ello se usa la palabra "misthou" (Lc 10:7). ${ }^{29}$

Una quinta instrucción se refiere a la forma de conducirse con los extraños a quienes visitan: "en cualquier ciudad o aldea donde entréis, averiguad quién es digno en ella" (10:11). El consejo era que tenían que buscar una casa que fuera digna de recibir a un mensajero de Dios. ${ }^{30}$ No puede ser en una casa de mala reputación moralmente, porque eso dañaría la utilidad del mensajero. No tenían que identificarse con nadie que podría ser un obstáculo para el cumplimiento de su misión.

La sexta instrucción es concerniente al saludo: "Al entrar en la casa, dadle vuestro saludo de paz" (v.12). El saludo de paz ${ }^{311}$ abre las puertas y es señal de la buena voluntad y aceptación mutua entre hospe-

\footnotetext{
${ }^{27}$ Henry, 178.

${ }^{28}$ Ibid., 179.

${ }^{29} \mathrm{Nichol}$, Comentario bíblico adventista, 5:365.

${ }^{30}$ Ibid.
}

${ }^{31} \mathrm{El}$ saludo judío: la paz (heb. Shalom, que comprendía toda clase de bendiciones) sea contigo (o con vosotros). Henry, 181. 
dador y visitante. ${ }^{32} \mathrm{Al}$ mismo tiempo presenta a un mensajero cortés y amable, un modelo de caballerosidad cristiana.

La séptima instrucción es con relación al contacto social. Después del saludo, los discípulos tendrían la conversación con los miembros de la familia y sobre ello tendrían más elementos de juicio sobre la disposición de ésta. Asimismo, "Si la casa es digna, vuestra paz vendrá sobre ella"; por esta razón, si se recibía con amor al mensajero y a su mensaje, esa familia recibiría todas las bendiciones que reportaba acoger a un representante de Cristo en ese hogar (Fil 4:7). Pero si la casa no era digna, esa paz que transmitía el mensajero volvía con él, en otras palabras, saldría de allí sin haber realizado el efecto al que estaba destinado (Is $45: 23) .{ }^{33}$

La octava instrucción tiene relación con el rechazo al mensaje. Jesús les dice: "salir de esa casa o de esa ciudad" (v.14). El evangelio no tiene por qué detenerse entre los que los rechazan. Cuando salgan de esa familia o de ese pueblo deben sacudir el polvo de sus pies, esto es señal de rompimiento de relaciones y el rechazo (ver Hch 13:51). ${ }^{34}$ Las consecuencias para las familias o pueblos que no escuchan el mensaje de los mensajeros se da en el versículo 15: "en verdad os digo que en el día del juicio será más tolerable el castigo para la tierra de Sodoma y Gomorra que para esa ciudad". A pesar de lo abominables que fueron Sodoma y Gomorra, los que rechazan el evangelio son considerados por el Señor como más abominables todavía, pues quiénes voluntariamente se niegan a oír la doctrina que habría de salvarlos tendrán que oír la sentencia de Dios en el juicio final. ${ }^{35}$

${ }^{32} \mathrm{El}$ saludo es importante para: (1) entrar mejor en el asunto, prepara el ambiente para la presentación de la Palabra de Dios (2) para ver qué clase de acogida se os dispensa, porque el que no recibe con amabilidad un saludo, no es de esperar que acoja con amabilidad un mensaje (3) para dar una buena impresión de vuestra persona, lo cual puede influir en la presentación que se va a dar del mensaje; Ibid., 180.

${ }^{33}$ Craig S. Keener, Comentario del contexto cultural de la Biblia: Nuevo Testamento, $3^{\text {ra }} \mathrm{ed}$. (El Paso, TX: Mundo Hispano, 2006), 345.

${ }^{34}$ Henry, 182.

${ }^{35}$ George R. Knight, Mateo: colección vida abundante la Biblia amplificada, 122. 


\section{Conclusión}

Después de haber analizado en la perícopa de estudio sobre los pasos que usó Jesucristo para el establecimiento de la misión, se ha llegado a las siguientes conclusiones:

1. Cada colaborador de Cristo debe sentir la motivación que Cristo sintió por las grandes multitudes que perecían en el pecado.

2. El llamado es esencial para el cumplimiento de la misión. Cristo extiende un llamado constante a sus hijos para que participen con él en el cumplimiento de la misión.

3. Los que participan de la misión son investidos con autoridad derivada de Jesucristo. Jesucristo como dueño de la misión y con potestad en el cielo y en la tierra delega algo de ese honor y de esa potestad en sus enviados.

4. El cumplimiento de la misión exige instrucción. La misión sin instrucción, no tiene origen en Cristo.

Que los pasos usados por Jesucristo para ser partícipes en la misión, haga reflexionar a cada mensajero en los métodos y pueda adoptar el mejor, a saber, el de Jesús. 